\title{
Simulation of Oil Production from Homogenous North Sea Reservoirs with Inflow Control using OLGA/Rocx
}

\author{
Sveinung M. Sund, Thomas Berg Iversen, Magnus S. Hansen, Jørgen Bohlin, Ole K. Vøllestad, Nora \\ C.I. Furuvik, Britt M. E. Moldestad \\ ${ }^{1}$ Department of Technology, University College of South-East Norway, Norway, \\ \{94.thomas.berg.iversen@gmail.n;msh 89ahotmail.com; okv1@hotmail.com; \\ sveinungsundegmail.com; britt.moldestadeusn.no; nora.c.i.furuvikeusn.no\}
}

\begin{abstract}
Advances in drilling technology have made long, horizontal wells the preferred method to extract oil from reservoirs in the Norwegian Sector. Horizontal wells give increased oil contact, enabling production from reservoirs with shallow, high viscosity oil columns. Under these conditions, early water or gas breakthrough is a major challenge. To postpone breakthrough, passive inflow control devices (ICD) are installed to even out the drawdown. However, a new technology called Autonomous Inflow Control Valve (AICVC) has the ability to autonomously close each individual inflow zone in the event of gas or water breakthrough. The objective of this paper was to study and compare these inflow control technologies. This was accomplished by conducting simulations in OLGA/Rocx. For this study, a highpermeability homogenous sandstone heavy oil reservoir was modelled based on data from the Grane oil field in the North Sea. Comparison of the oil production from the simulations with ICD and AICV completion was performed. The results, based on a time interval of 600 days, show that the oil production is $8 \%$ less and the water production is $43 \%$ less if AICV is used compared to ICD. This indicates that AICV has the potential to reduce the water production significantly in a homogeneous reservoir.
\end{abstract}

Keywords: Inflow control, ICD, AICV, oil reservoir, oil production, breakthrough, multiphase flow, OLGA, Rocx.

\section{Introduction}

A major challenge in oil production is to increase the ability to recover the oil that is present in the reservoir. Estimates show that although the oil is localized and mobile, about half of the oil remains in the reservoir after shutdown. Therefore, there are strong incentives for using technologies that can increase the oil production and recovery. Two factors are of particular importance in order to increase oil production and recovery; obtaining maximum reservoir contact and preventing the negative effects of early gas or water breakthrough. (Mathiesen et al, 2014) Long horizontal wells are used to obtain maximum reservoir contact. In the North Sea, the oil columns are very thin, and it is therefore a challenge to avoid early water and gas breakthrough to the well. Inflow controllers are implemented to limit early gas and water breakthrough. (Terry and Rogers, 2014; Geoscience News and
Information, 2017) Inflow control devices adjust the inflow volume to the well to avoid high volume flow in zones with high permeability or high drawdown. This paper focuses on studying the effect of inflow controllers in a homogeneous oil reservoir with an underlying water aquifer in the North Sea. Two types of technologies were studied; a passive inflow control device (ICD) and an autonomous inflow control valve (AICV). Passive ICD is capable of equalizing the production along the well. AICV can close for unwanted fluids when breakthrough occurs. Several studies have been carried out to investigate the effect of inflow controllers in different types of reservoirs. (Furuvik and Moldestad, 2017; Ugwu and Moldestad, 2016; Abbasi and Moldestad, 2016; Jonskås et al., 2016) Near-well simulation have been performed by using simulation tools like Eclipse, OLGA/Rocx, Aspen/Hysys and NETool. The conclusion has been that there is a high potential of increasing the oil recovery by using inflow controllers. This study includes OLGA/Rocx simulations of the oil production from the Grane field in the North Sea. The Grane field is often presented as a homogeneous reservoir, but still fractures and heterogeneities are observed in parts of the field (Skotner, 1999). This paper focuses on oil production from homogeneous parts of the Grane field.

\subsection{Driving forces for oil production}

During oil production from a reservoir, the driving force is the pressure difference between the reservoir and the well. It is important to maintain a sufficient reservoir pressure to sustain an acceptable oil production rate. During oil production, the reservoir pressure decreases, and if it drops too low, the oil production stops. (Nasjonal Digital Læringsarena, 2016) The pressure in the reservoir can be maintained by gas or water drive. Some reservoirs have a large gas cap above the oil layer that acts as a buffer for the reservoir pressure. During oil production, the gas expands and pushes the oil towards the well. This is described as gas cap drive. (Nasjonal Digital Læringsarena, 2015) Some reservoirs have a large aquifer below the oil layer. In these types of reservoirs, the water is replacing the oil during the oil production, and since the aquifer is significantly larger than the oil reservoir, the reservoir pressure will decrease slowly over time. Water does not expand in the 
reservoir, but due to the size of the aquifer, water flows into the reservoir and oil will be pushed towards the well. (Nasjonal Digital Læringsarena, 2015; Petrowiki, 2015) However, after years of production, the reservoir pressure will decrease. At that point injection of water into the reservoir can be used to maintain the reservoir pressure. Injection wells are installed in the reservoir for this purpose. The reservoir conditions are essential when determining whether water injection, gas injection or a combination of these are most effective. (Oljedirektoratet, 2009) Treated sea water, or formation water, can be used for the water injection. Natural gas from the reservoir or other reservoirs are often used in gas injection systems, but other gases such as nitrogen and carbon dioxide can also be used as pressure support in mature oil fields (Nasjonal Digital Læringsarena, 2017). In the present study, heavy oil production from a homogeneous reservoir with an underlying aquifer is considered.

\subsection{Horizontal wells}

The oil reservoirs at Grane have thin oil columns. Long horizontal wells are used to increase the reservoir contact and thereby obtain higher oil recovery (Terry and Rogers, 2014; Geoscience News and Information, 2017). The frictional pressure drop in the well is proportional to the length of the well as given by:

$$
\Delta P=f \cdot \frac{L}{D} \cdot \frac{\rho \cdot v^{2}}{2}
$$

where $f$ is the friction factor, $L$ is the length of the well, $D$ is the diameter of the well, $v$ is the average fluid velocity and $\rho$ is the fluid density.

Due to frictional pressure drop along the well, the driving forces for oil production are different from one location to another in the well. This is called the heel (low pressure) - toe (high pressure) effect. In a homogeneous reservoir, the oil production rate will be significantly higher in the heel than in the toe, and this may lead to early water or gas breakthrough in the heel section. Figure 1 illustrates a long horizontal well with water and gas breakthrough in the heel section.

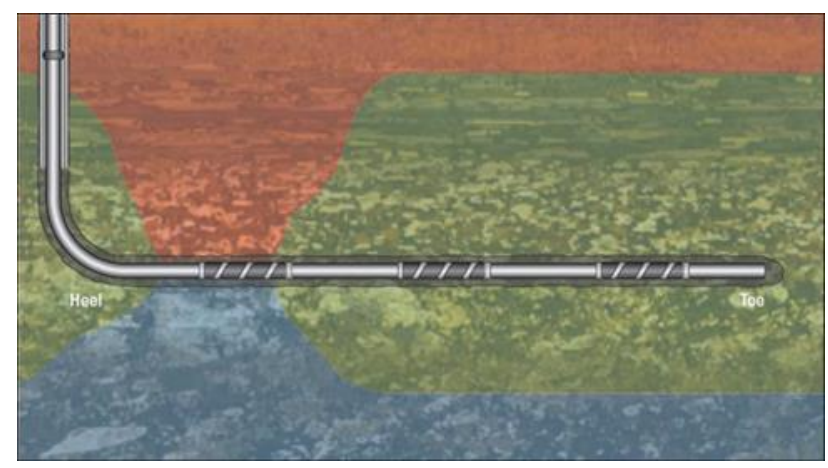

Figure 1. Horizontal well with gas and water breakthrough in the heel section. (Ellis et al, 2010)

Breakthrough of unwanted fluids to the production well is a big challenge for the oil industry. Different types of inflow controllers are developed to avoid early breakthrough and even choke or close off zones when breakthrough occurs. In the present study, two types of inflow controllers have been considered; a passive inflow controller (ICD) and an autonomous inflow control valve (AICV).

\subsubsection{Inflow controllers}

In this study, a standard nozzle ICD was used. ICDs are designed to give a more uniform oil production along the well, and the technology has opened up for production from reservoirs with thin oil columns. The capacity of an ICD is often given as the ICD strength, which is defined as the pressure drop over the ICD when $1 \mathrm{~m}^{3}$ of fluid passes through per hour. The pressure drop highly depends on the nozzle diameter and the density of the fluid, and less on the viscosity. ICDs are capable of delaying the gas/water breakthrough significantly. (Al-Khelaiwi and Davis, 2007). Well completion with ICDs includes a large number of ICDs equally distributed along the well. ICDs neither choke nor close for the undesired fluids after breakthrough. In order to avoid overloading the downstream separation facilities, the whole well has to be choked. Reservoir simulations have been used for different types of ICD completion and the results have been useful for ICD design. (AlKhelaiwi and Davis, 2007) Krinis \& al. used the reservoir model NETool to determine the optimal number and location of ICDs, and they stated that the simulations were the key factor in the successful optimization of the horizontal well performance (Krinis et al, 2009). Figure 2 shows a nozzle ICD installed in a pipeline. The arrows show the direction of the fluid flow through the sand screen via the nozzle ICD and into the well.

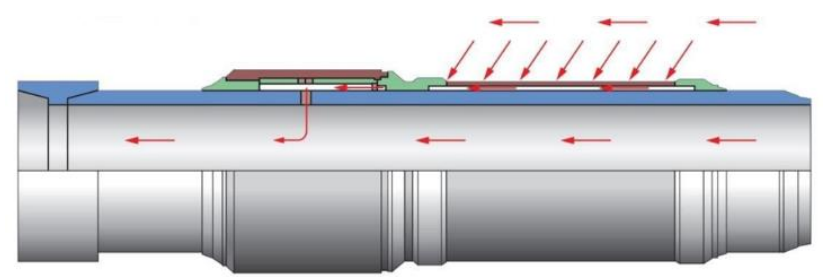

Figure 2. Nozzle ICD installed in a pipe section. (Ellis et al., 2010)

This paper also includes the use of AICV in oil production. AICV is completely self-regulating and does not require any electronics or connection to the surface. AICV is capable of both delaying water/gas breakthrough and to close almost completely for the unwanted fluids when breakthrough occurs. The valves will locally close in the zones with water or gas breakthrough, and simultaneously produce oil from the other zones along the well. The AICV technology enables drilling of longer wells. The technology eliminates the gas and water breakthrough problems, and removes the risk, cost and requirement for separation, transportation and handling of unwanted 
fluids. (Aakre et al., 2013) Near-well simulations with Rocx have shown the potential of increased oil recovery with AICV completion. (Aakre et al., 2013) Figure 3 shows a drawing of the AICV in open and closed position. The thick blue arrow indicates the fluid flow into the AICV, and the two horizontal arrows represents the outlet from the AICV to the well. The yellow area is a piston, and this piston is moving from open to closed position depending on the viscosity of the fluid surrounding the AICV. The principle of the AICV technology is described in detail by Mathiesen et al., Aakre et al. and Ransis et al. (Mathiesen et al., 2014; Aakre et al.; 2013; Ransis et al., 2016)
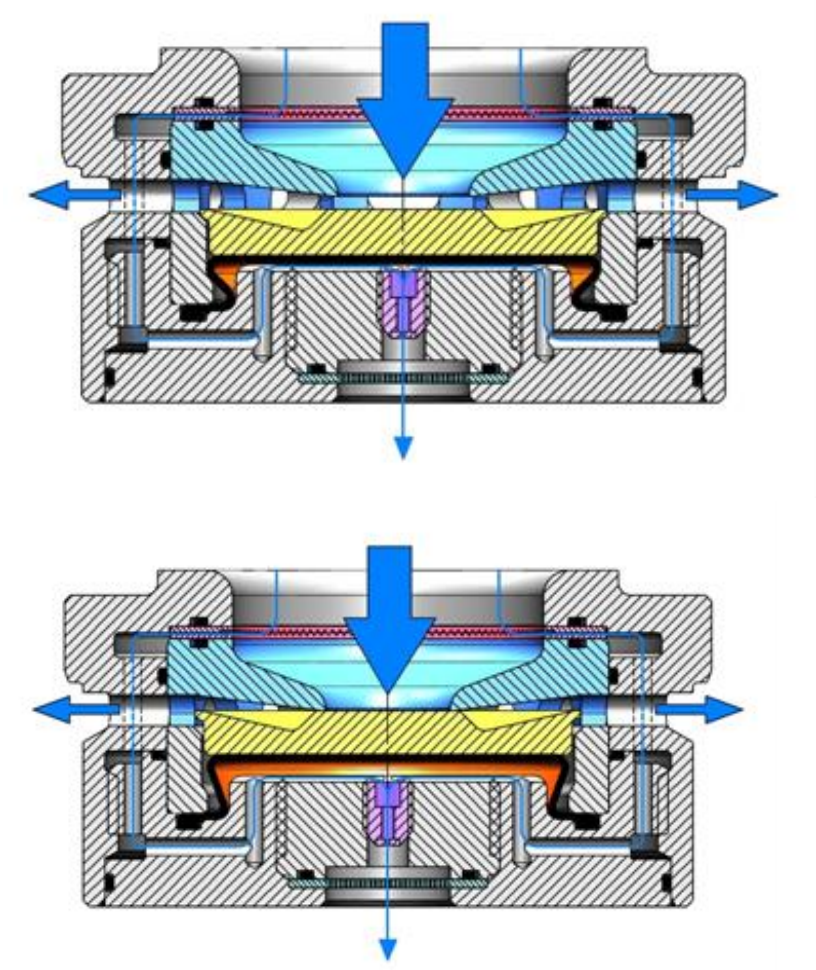

Figure 3. Drawing of AICV in open and closed position. (Aakre, et al., 2014)

\section{Simulation set-up}

Simulations of oil production are carried out by using the near well simulation tool Rocx in combination with OLGA.

\subsection{Rocx}

Rocx is a three-dimensional transient near well simulation tool and is used to simulate three-phase flow in permeable rocks. Rocx gives information about changes in pressure, temperature and fluid saturation in the reservoir with time. The information from the near well simulations is transferred to OLGA.

\subsubsection{Grid}

The dimensions of the reservoir and the position of the well are defined in Rocx. The reservoir is divided into 3900 control volumes; 10 in x-direction, 39 in $y$ direction and 10 in z-direction. The simulated reservoir is $1219 \mathrm{~m}$ in $\mathrm{x}$-direction, $308 \mathrm{~m}$ in $\mathrm{y}$-direction and $31 \mathrm{~m}$ in $\mathrm{z}$-direction. The grid sizes are $121.9 \mathrm{~m}$ in the $\mathrm{x}$ direction. A normal well in the North Sea consists of pipe sections of $12.19 \mathrm{~m}$. Each pipe section is equipped with sand screen and one or more inflow controllers. In the present study, pipe sections of $121.19 \mathrm{~m}$ are used to reduce the simulation time. The simulations are performed for the Grane field, where the height of the oil column is typically $31 \mathrm{~m}$ (Skotner, 1999). The width of the reservoir is chosen as $308 \mathrm{~m}$ to secure sufficient initial volume of oil. The grid sizes in the $\mathrm{x}-$ and $\mathrm{z}$ directions are constant, whereas in the y-direction the grid sizes are decreasing towards the wellbore. This is done to get a better prediction of the distribution of the fluids in the reservoir, the water breakthrough time, and the coning effect. The well is located about $9 \mathrm{~m}$ above the lower boundary of the reservoir. The water-oil boundary is in the bottom of the reservoir. Figure 4 shows the final grid including the position of the well.

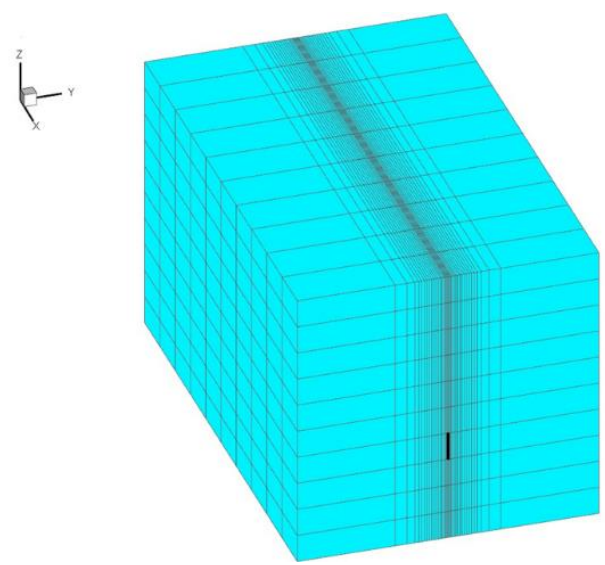

Figure 4. Pipe section with nozzle ICD.

\subsubsection{Permeability}

This paper presents the simulations of a homogeneous reservoir. The horizontal ( $\mathrm{x}-\mathrm{y})$ permeability is $8000 \mathrm{mD}$ and the vertical (z) permeability is $800 \mathrm{mD}$, corresponding to $1 / 10$ of the horizontal permeability. The relative permeability is the ratio of the effective permeability to the absolute permeability, and is highly dependent on the type of reservoir. Grane is modelled as a water-wet sandstone reservoir. In water-wet conditions, a thin film of water coats the surface of the rock, which is desirable for efficient oil transport in the reservoir. The relative permeability for oil and water at Grane is calculated based on the Corey correlation. The Corey model is derived from capillary pressure data and is accepted as a good approximation for relative permeability curves in a two-phase flow. The required input data is limited to the irreducible water saturation 
(Swc) and the residual oil saturation (Sor), and their corresponding relative permeability. (Furuvik and Moldestad, 2017; Tangen, 2017) Swc defines the maximum water saturation that a reservoir can retain without producing water, and Sor refers to the minimum oil saturation at which oil can be recovered by primary and secondary oil recovery. The relative permeability curves implemented in the simulations are presented in Figure 5. The blue line represents the relative permeability for water (Krw) and the red line represents the relative permeability for oil (Kro).

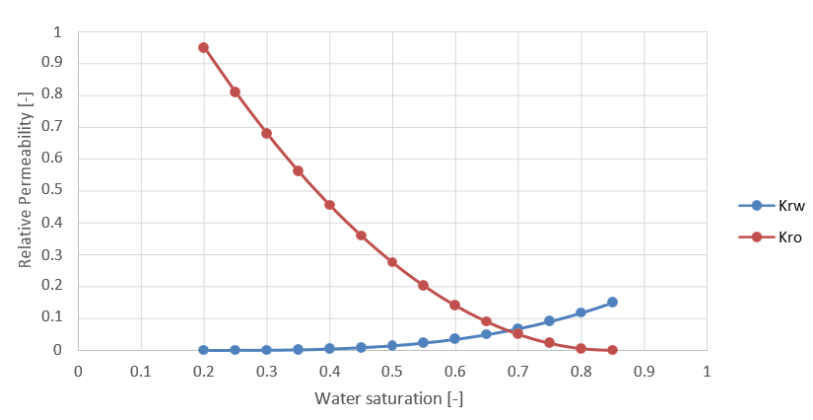

Figure 5. Relative permeability curves for water and oil.

The calculation and implementation of the relative permeability curves in Rocx, is described in detail by Furuvik and Moldestad (Furuvik and Moldestad, 2017).

The reservoir and fluid properties used as input to Rocx are summarized in Table 1.

Table 1. Input data to Rocx.

\begin{tabular}{|l|l|}
\hline Fluid properties & $12 \mathrm{cP}$ \\
\hline Oil viscosity & $895 \mathrm{~kg} / \mathrm{m}^{3}$ \\
\hline Oil density & Black oil \\
\hline Oil PVT model & 0.33 \\
\hline Reservoir properties & $8000-8000-800 \mathrm{mD}$ \\
\hline Porosity & $176 \mathrm{bar}$ \\
\hline $\begin{array}{l}\text { Permeability } \\
\text { (x-y-z- direction) }\end{array}$ \\
\hline Pressure & $176 \mathrm{bar}$ \\
\hline Initial conditions & $76^{\circ} \mathrm{C}$ \\
\hline Pressure & 0.8 \\
\hline Temperature & $176 \mathrm{bar}$ \\
\hline Oil saturation & \\
\hline Boundary conditions & \\
\hline Water drive from the bottom & 17 \\
\hline
\end{tabular}

\subsection{OLGA}

OLGA is a one-dimensional transient dynamic multiphase simulator used to simulate flow in pipelines and connected equipment. OLGA consists of several modules depicting transient flow in a multiphase pipeline, pipeline networks and processing equipment. The OLGA simulator is governed by conservation of mass equations for gas, liquid and liquid droplets, conservation of momentum equations for the liquid phase and the liquid droplets at the walls, and conservation of energy mixture equation with phases having the same temperature (Thu, 2013; Schlumberger 2007)

\subsubsection{Setup in OLGA}

The set-up in OLGA includes annulus, pipeline, packers and inflow controllers. Annulus is the space between the rock and the pipeline. Figure 6 shows a drawing of the location of the annulus and the well in the reservoir.
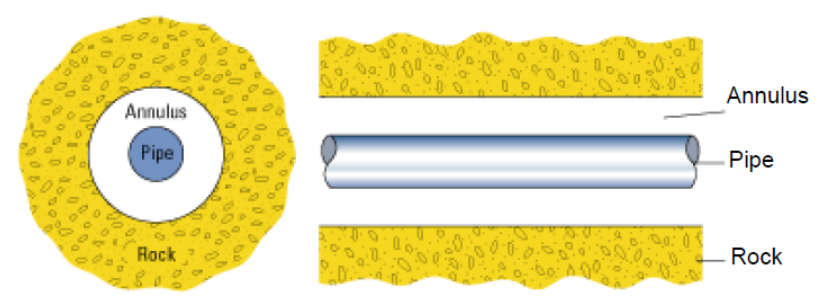

Figure 6. A drawing of the pipe and the annulus. (Schlumberger, 2007)

The OLGA version used in this project does not have any available routine for annulus simulations. The production well and the annulus are therefore implemented as two separate pipelines, as presented in Figure 7. The lower and the upper pipelines illustrate the annulus and the production well respectively.

In OLGA, the inflow controllers are defined as valves. ICDs are passive inflow controllers and are modelled as fully open valves. The AICVs are operating in open or closed position depending on the properties of the surrounding fluid.

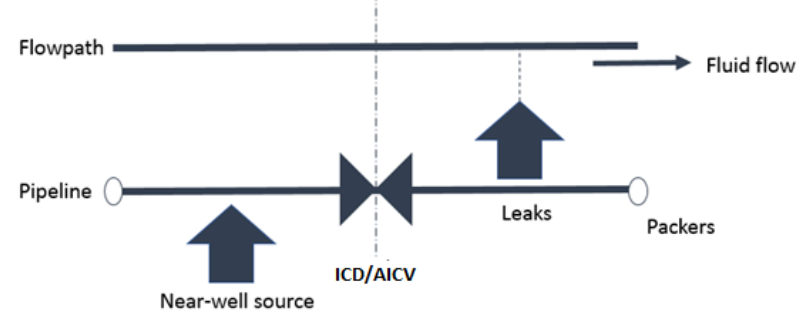

Figure 7. Representation of single zone of well. (Timsina, 2017)

Figure 8 illustrates one pipe section including the flow from the reservoir (NWSOUR-2) to annulus, one inflow controller (VALVE2), two packers (PACKER and PACKER-2) and the flow through the inflow controller to the production well (LEAK). 


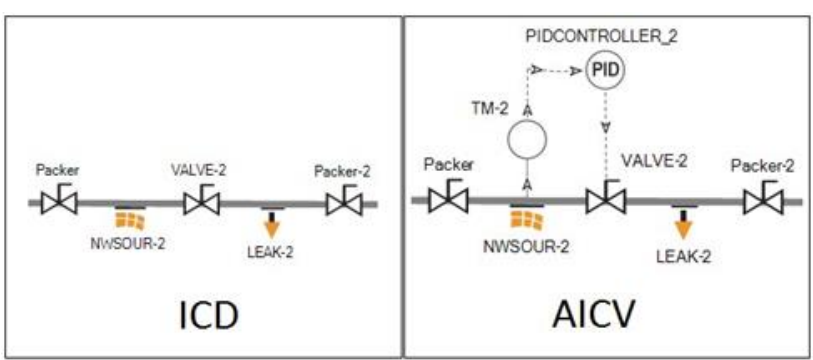

Figure 8. Set-up of ICD and AICV in OLGA.

The ICD and AICV both have an inlet diameter of 19.5 $\mathrm{mm}$. There are no options to choose autonomous inflow controllers in OLGA, and transmitters and PIDs are used to model the functionality of the AICVs. The transmitters register the water cut (WC), and if the WC is higher than the set point given for the PID, the AICV starts to close. When the AICVs are in closed position, the flow area of the valves is reduced to $0.8 \%$ of the fully open valve area. The diameters of the pipeline and the annulus are set to $0.1397 \mathrm{~m}(5.5 ")$ and $0.2159 \mathrm{~m} \mathrm{(8.5")}$ respectively. The roughness of the well is assumed to be $1.5 \cdot 10^{-4} \mathrm{~m}$. The production well has a length of $1279.5 \mathrm{~m}$ and is divided into 10 sections of $\mathrm{meach}$, and one outlet part $(60.95 \mathrm{~m})$ including a PID controller to adjust the total flow rate to the downstream facilities. Figure 9 illustrates the outlet section of the well including the choke and the PID controller.

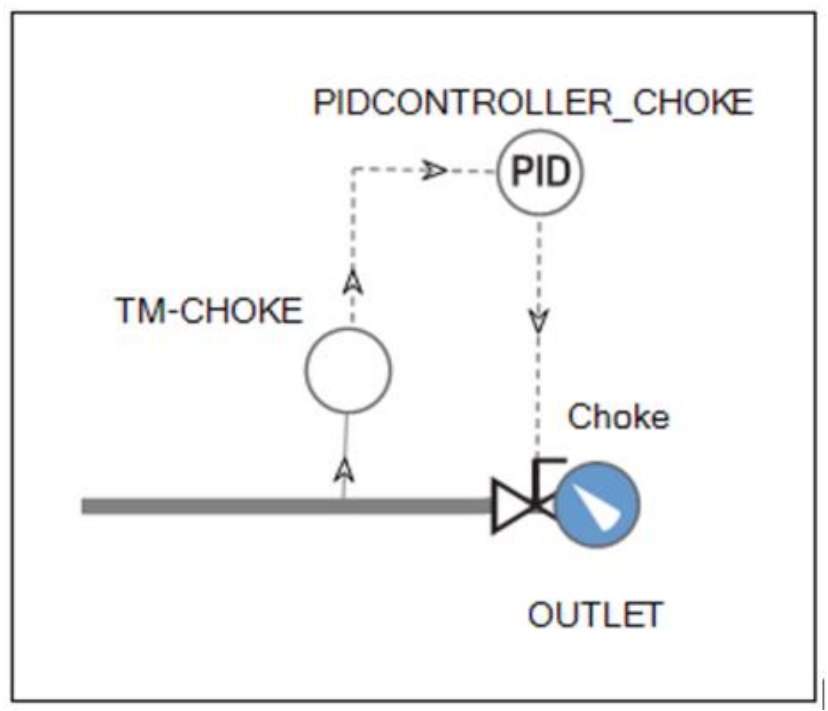

Figure 9. Flow control at the outlet of the well.

The PID is controlling the total flow rate, and the set point is $1200 \mathrm{~m}^{3} /$ day. The set point value is calculated based on production data from Grane. The PID controller parameters are presented in Table 2.
Table 2. PID controller parameters.

\begin{tabular}{|l|l|}
\hline Parameter & Value \\
\hline Set point & $1200 \mathrm{~m}^{3} /$ day \\
\hline Initial opening & $0.10 \%$ \\
\hline Maximum opening & $100 \%$ \\
\hline Minimum opening & $0.10 \%$ \\
\hline Amplification & -0.18 \\
\hline Sample time & $60.0 \mathrm{~s}$ \\
\hline Integral time & $540 \mathrm{~s}$ \\
\hline Derivative time & $0.00 \mathrm{~s}$ \\
\hline
\end{tabular}

\section{Results}

Based on the input data in Rocx and OLGA, simulations were performed for 600 days of production. The results presented are volume rates of oil, and accumulated oil and water volume, for ICD and AICV. The closure characteristics for the AICVs is also presented. In addition, the results from a time step sensitivity analysis are included. Malagalage and Halvorsen did grid resolution tests for the same system (Malagalage and Halvorsen, 2015). The recommended grid resolution is utilized in this study.

\subsection{Time step sensitivity analysis}

Preliminary simulations were performed to study the influence of the minimum time step size on the oil and water production rates. Minimum and maximum time steps are input values in OLGA. During the simulations, OLGA will use the most convenient time step between the minimum and the maximum. When small minimum time steps are used, the simulations are more time-consuming. Large time steps result in less total simulation time, but it will also result in lower accuracy. A time sensitivity analysis was performed to study the consequences of increasing the minimum time step (MinDT) for the ICD and AICV simulations. The values for MinDT were chosen as $0.001 \mathrm{~s}$ and $50 \mathrm{~s}$. Other values for MinDT, like 70s, 80s, $90 \mathrm{~s}$ and $100 \mathrm{~s}$, were also tested, but were too high and the simulations stopped. The consequence of using a MinDT of $50 \mathrm{~s}$ compared to $0.001 \mathrm{~s}$ was investigated by comparing the number of days before key events occur. The events were defined as first water breakthrough (O1), $65 \%$ water cut in the first zone $(\mathrm{O} 2), 65 \%$ water cut in all zones $(\mathrm{O} 3)$ and $70 \%$ water cut in the total production (O4). The results are shown in Table 3.

Table 3. Results from the time sensitivity tests.

\begin{tabular}{|l|l|l|l|l|l|}
\hline MinDT & Type & $O 1$ & $O 2$ & $O 3$ & $O 4$ \\
\hline $50 \mathrm{~s}$ & ICD & $36 \mathrm{~d}$ & $122 \mathrm{~d}$ & - & $452 \mathrm{~d}$ \\
\hline $0.001 \mathrm{~s}$ & ICD & $37 \mathrm{~d}$ & $118 \mathrm{~d}$ & - & $455 \mathrm{~d}$ \\
\hline $50 \mathrm{~s}$ & AICV & $36 \mathrm{~d}$ & $122 \mathrm{~d}$ & $319 \mathrm{~d}$ & - \\
\hline $0.001 \mathrm{~s}$ & AICV & $37 \mathrm{~d}$ & $109 \mathrm{~d}$ & $264 \mathrm{~d}$ & - \\
\hline
\end{tabular}


$\mathrm{O} 1, \mathrm{O} 2$ and $\mathrm{O} 4$ show that ICD is very little affected by the increase in time step. However, the results indicate that AICV is more sensitive to the size of MinDT. This is probably due to large variations in volume flow through the valves during the period of closing. It can be concluded that the closing time for the AICVs increases with decreasing MinDT.

Table 4 presents the effect of MinDT on the accumulated oil and water volumes during 600 days of production. The results show that the accumulated oil and water production with ICD are almost insensitive to the variation in MinDT. This is also the case for oil when AICV is used, although the water production decreases with about $5 \%$ when MinDT is increased from $0.001 \mathrm{~s}$ to $50 \mathrm{~s}$. Based on these results, it was found that 50s would be an adequate MinDT.

Table 4. Accumulated production for different MinDT.

\begin{tabular}{|l|l|l|l|}
\hline $\begin{array}{l}\text { MinDT } \\
{[\mathrm{s}]}\end{array}$ & Type & $\begin{array}{l}\text { Acc. Oil } \\
{\left[10^{5} \mathrm{~m}^{3}\right]}\end{array}$ & $\begin{array}{l}\text { Acc. water } \\
{\left[10^{5} \mathrm{~m}^{3}\right]}\end{array}$ \\
\hline 0.001 & ICD & 2.63 & 4.58 \\
\hline 50 & ICD & 2.60 & 4.60 \\
\hline 0.001 & AICV & 2.45 & 2.76 \\
\hline 50 & AICV & 2.39 & 2.61 \\
\hline
\end{tabular}

\subsection{Oil and water production with ICD and AICV}

The simulations using OLGA/Rocx were performed with ICD and AICV completed horizontal wells. The simulations were performed for 600 days, and the set point for the water cut through AICVs was used as $65 \%$. The set point for the total flow was specified as 1200 $\mathrm{m}^{3} /$ day. The minimum time step was set to $50 \mathrm{~s}$ and the maximum time step was $3600 \mathrm{~s}$. Figure 10 shows the oil production rates with time for ICD and AICV. The plot is divided into three time intervals, T1, T2 and T3. T1 presents the period when AICV are fully open, and AICVs and ICDs are operating at the same production rates. During T2, the AICVs are producing more oil than the ICDs and in T3, when all the AICVs are closing, ICDs are producing more oil than AICVs.

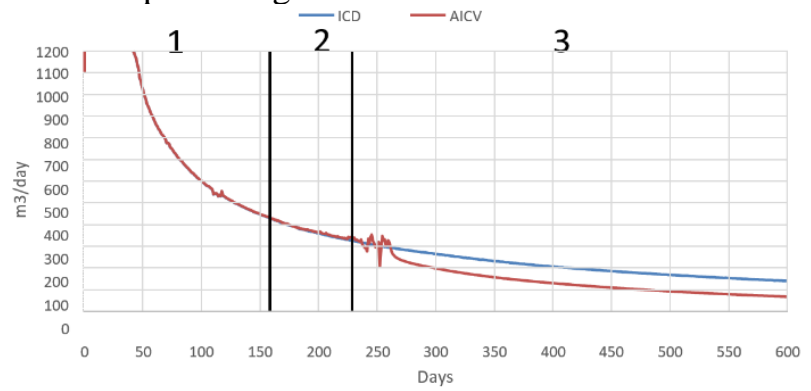

Figure 10. Volume flow rate of oil through ICD and AICV.

The production rates are equal for the two types of inflow controllers until the water cut through the first AICV exceeds 65\%. This occurs after 163 days of production. When the first AICV starts closing, more oil is produced through the other zones in the well due to increased capacity. In the same period, the ICDs are producing less oil and more water than the AICVs. After 232 days, when all the AICVs are closing and the total capacity is limited by the AICVs, the ICDs produce more oil than the AICVs.

Figure 11 shows the closing characteristics for AICV. All the AICVs start to close during a period of about 50 days, and it takes about 70 days from the first AICV starts closing until all the valves are $70 \%$ closed. All the valves start to close within a short period due to a rather low frictional pressure drop in the well. The frictional pressure drop creates the heel-toe effect, and the time intervals between the closing of the different AICVs along the well are increasing with increasing pressure drop. Because the heel-toe effect influences the watercut of each section, the AICVs in the heel section start closing first.

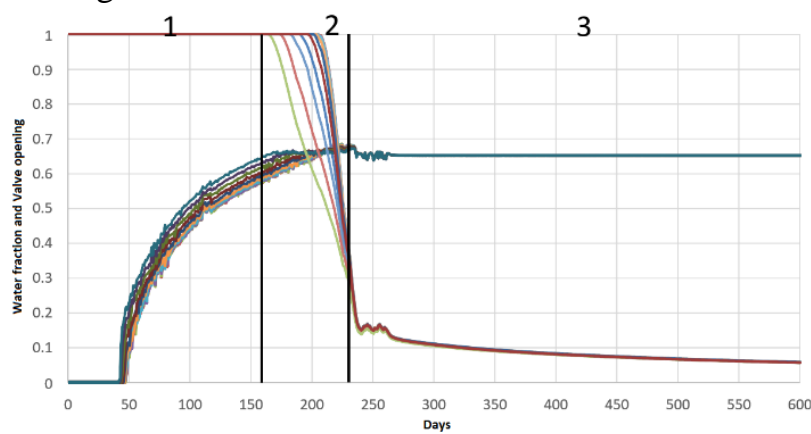

Figure 11. Closure characteristic for the AICVs.

The instability in the oil production after about 250 days is due to the high activity in the well when all the AICVs are closing. The instabilities are probably due to numerical diffusion.

Figure 12 shows the accumulated oil production for AICV and ICD versus time. The oil production is slightly higher for AICV than ICD in T2 and lower in T3.

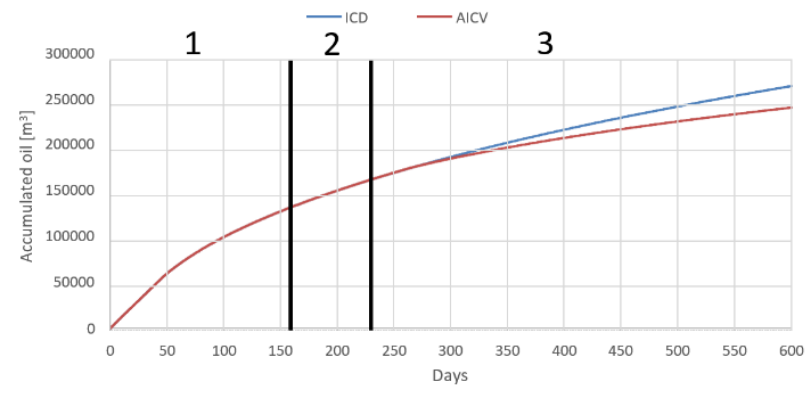

Figure 12. Accumulated oil production for ICD and AICV.

Figure 13 presents the water production data for ICD and AICV. During time period T3, ICD is producing significantly more water than AICV. 


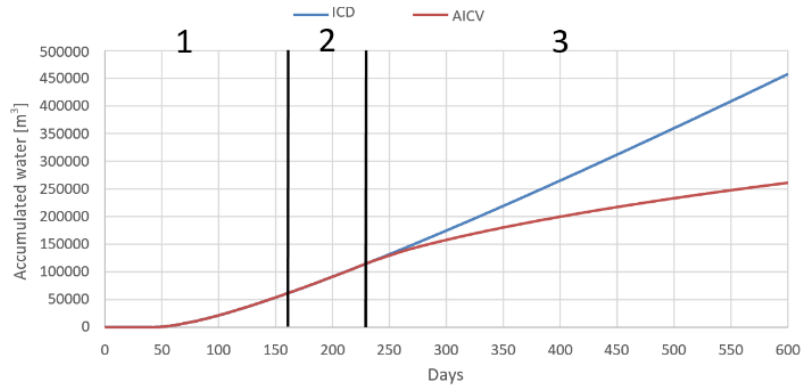

Figure 13. Accumulated water production for ICD and AICV.

Table 5 and Table 6 show a comparison of the accumulated water and oil production for ICD and AICV. The accumulated production is given for the different time intervals and the total simulation period. The total oil production is $9 \%$ less and the water production is $43 \%$ less if $\mathrm{AICV}$ is used compared to ICD.

Table 5. Accumulated oil and water production through AICVs and ICDs.

\begin{tabular}{|l|c|c|}
\hline $\begin{array}{l}\text { Time } \\
\text { interval }\end{array}$ & $\begin{array}{c}\text { Accumulated water } \\
\text { ICD }\left[\mathrm{m}^{3}\right]\end{array}$ & $\begin{array}{c}\text { Accumulated water } \\
\text { AICV }\left[\mathrm{m}^{3}\right]\end{array}$ \\
\hline $\mathrm{T} 1$ & 63095 & 63095 \\
\hline $\mathrm{T} 2$ & 53901 & 53702 \\
\hline $\mathrm{T} 3$ & 340809 & 143997 \\
\hline Total & 457805 & 260794 \\
\hline
\end{tabular}

Table 6. Accumulated oil and water production through AICVs and ICDs.

\begin{tabular}{|l|c|c|}
\hline $\begin{array}{l}\text { Time } \\
\text { interval }\end{array}$ & $\begin{array}{c}\text { Accumulated oil } \\
{\left[\mathrm{m}^{3}\right] \mathrm{ICD}}\end{array}$ & $\begin{array}{c}\text { Accumulated oil } \\
{\left[\mathrm{m}^{3}\right] \mathrm{AICV}}\end{array}$ \\
\hline T1 & 132591 & 132591 \\
\hline T2 & 28899 & 29058 \\
\hline T3 & 100693 & 77081 \\
\hline Total & 262183 & 238730 \\
\hline
\end{tabular}

The heel-toe effect increases with high flow rates, small pipe diameter and high roughness. In the case simulated, the frictional pressure drop was relatively low, and all the AICVs closed during a short period. In addition, the WC set-point was set low; 65\%, and all the AICVs started to close after a short time of production. The oil production rate for the AICV case was therefore relatively low. The AICV technology is reversible, which means that the valve will open again when the $\mathrm{WC}$ is reduced to below $65 \%$. However, in the simulations there is no boundary oil source, and no new oil will come from the surrounding parts of the reservoir and increase the oil fraction around the well. The reversible function of AICV can be taken into consideration in further studies by changing the boundary conditions.

\section{Conclusion}

Oil production from the Grane field in the North Sea was simulated with the near-well simulation tool Rocx in combination with OLGA. A long horizontal well was modelled, and it was assumed that the reservoir was homogeneous with a horizontal permeability of $8000 \mathrm{mD}$. Two cases were simulated, one with passive inflow control devices (ICDs) and one with autonomous inflow control valves (AICVs) installed along the well. A time step sensitivity test was carried out to find the largest minimum time step that can be used while maintaining sufficient accuracy. It was concluded that a minimum time step of 50s was acceptable for simulations with both AICV and ICD. PID controllers were used to adjust flow through each AICV, with a desired value of $65 \%$ WC. A PID controller was also used to control the total volumetric flow rate for the two cases, with a desired value of $1200 \mathrm{~m}^{3} /$ day. The simulations were run for 600 days. WC of $65 \%$ in the heel section was registered after 163 days, and the AICV started to close. In time interval 163-232 days, AICV produces slightly more oil than ICD. After 232 days, the ICD well produces more oil than the AICV well, but also considerably more water, due to a higher total production. The total oil production was $9 \%$ less and the water production was $43 \%$ less for the AICV well compared to the ICD well. This indicates that for oil production from homogenous reservoirs with small differences in pressure and water cut along the well, the benefits of AICV technology are small compared to ICD completion. For real AICV installations, the AICVs should be designed for the reservoir conditions and should not limit the total production at an economically acceptable water cut.

\section{References}

Haavard Aakre, Britt Margrethe Halvorsen, Bjørnar Werswick and Vidar Mathiesen. Smart Well With Autonomous Inflow Control Valve Technology. I: 18th Middle East Oil \& Gas Show and Conference (MEOS), March $10-13,2013$.

Aakre, Haavard; Halvorsen, Britt Margrethe; Werswick, Bjørnar; Mathiesen, Vidar. Autonomous inflow control valve for heavy and extra-heavy oil. I: 2014 SPE Heavy and Extra Heavy Oil Conference: Latin America. Society of Petroleum Engineers 2014 ISBN 978-1-61399-345-3.

Arash Abbasi, Britt M. E. Moldestad, Simulation of light oil production from heterogeneous reservoirs: Well completion with inflow control devices. I: 2016 9th EUROSIM Congress on Modelling and Simulation Oulu, Finland 12-16 September 2016. IEEE 2016 ISBN 978-1-5090-4119-0. pp. 836-841.

T. Ellis, A. Erkal, G. Goh, T. Jokela, S. Kvernstuen, E. Leung, et al. Inflow Control Devices- Raising Profiles, Oilfield Review, pp. 30-31, 2010. 
Nora C. I Furuvik and Britt M. E. Moldestad. Distribution of $\mathrm{CO} 2$ in Fractured Carbonate Reservoirs. International Journal of Energy Production and Management, Volume 2 (1) pp. 28-38, 2017.

Geoscience News and Information. Directional and Horizontal Drilling in Oil and Gas Wells, Geology.com, date: 23.04.2017. Available from: http://geology.com/articles/horizontal-drilling/

M. H. Jonskås, V. Mathiesen and B. M.E. Moldestad. Heavy oil production with energy effective Steam Assisted Gravity Drainage. Energy Quest 2016, 2nd International Conference on Energy Production and Management in the 21st Century, September 6th-8th, Ancona, Italy, 2016.

Ransis Kais, Vidar Mathiesen, Haavard Aakre and Glenn Woiceshyn. First autonomous Inflow Control Valve (AICV) Well Completion Deployed in a Field under an EOR (Water \& CO2 Injection) Scheme, SPE-181552-MS, 2016.

F.T. Al-Khelaiwi and D.R. Davies. Inflow Control Devices: Application and Value Quantification of a Developing Technology, International Oil Conference and Exhibition in Mexico, 27-30 June 2007, Veracruz, Mexico. 2007

Dimitrios Krinis, Drew Hembling, Naseem Al-Dawood and Sadiq Al-Qatari, Sam Simonian and Giovanni Salerno. Optimizing Horizontal Well Performance in Non-Uniform Pressure Environments Using Passive Inflow Control. OTC 20129 Texas, May, 2009.

Anjana Malagalage and Britt M. Halvorsen. Near Well Simulation and Modelling of Oil Production From Heavy Oil Reservoirs. Linköping Electronic Conference Proceedings 2015 (119) s. 289-298. , 2015.

Vidar Mathiesen, Haavard Aakre and Bjørnar Werswick. The Next Generation Inflow Control-the Next Step to Increase Oil Recovery on the Norwegian Continental Shelf, SPE 169233, 2014.

Nasjonal Digital Læringsarena. Fagstoff/Leting og Boring/ Produksjonsoppstart. ndla.no, date 10.05.2017. Anna Aabø, 2016. Available from:

http://ndla.no/nb/node/156340?fag=137414

Nasjonal Digital Læringsarena. Fagstoff/Leting og Boring/ Drivmekanismer i reservoaret. ndla.no, date: 01.05.2017. Anna Aabø, 2015. Available from: http://ndla.no/nb/node/153039?fag=137414

Nasjonal Digital Læringsarena. Fagstoff/Leting og Boring/ Gassinjeksjon i reservoaret. ndla.no, date: 28.04.2017. Anna Aabø, 2015.Available from: http://ndla.no/nb/node/153041?fag=137414

Oljedirektoratet. Verkt $\varnothing \mathrm{y}$ for $\varnothing \mathrm{kt}$ utvinning. npd.no, date: 28.04.2017. 2009. Available from:

http://www.npd.no/no/Tema/Okt-

utvinning/Temaartikler/Verktoy-for-okt-utvinning-/
Petrowiki. Waterdrive reservoirs. Petrowiki.org, date: 21.04.2017. 2015. Available from:

http://petrowiki.org/Waterdrive_reservoirs

Schlumberger. Rocx Reservoir Simulator. 1.2.5.0 edit, 2007.

Schlumberger. Fundamentals of Wettability. Oilfield Review, number 2, Volume 19, page 66-71. Summer 2007.

P.Skotner. Evaluation of $\mathrm{CO} 2$ flooding on the Grane Field, Norsk Hydro pp.4, 1999.

Mathias Tangen. Wettability Variations within the North Sea Oil Field Frøy. Master Thesis, Norwegian University of Science and Technology, Department of Petroleum Engineering and Applied Geophysics, 2012.

R.E. Terry and J.B. Rogers. Introduction to Petroleum Reservoirs and Reservoir Engineering. Applied Petroleum Reservoir Engineering, third edition, 2014.

E. S. Thu. Modeling of transient $\mathrm{CO} 2$ flow in pipeline and well. Master Thesis, Norwegian University of Science and Technology, Trondheim, 2013.

Ramesh Timsina. Near-well simulations and modelling of oil production from reservoir. Master Thesis, University College of South-East Norway, Faculty of Technology, Natural sciences and Maritime sciences, 2017.

Ambrose A. Ugwu and Britt M. E. Moldestad, Simulation of Horizontal and Vertical Water Flooding in a Homogeneous Reservoir using ECLIPSE, 9th EUROSIM Congress on Modelling and Simulation, EUROSIM 2016, September 12th -16th, Oulu, Finland, 2016. 